\title{
Capítulo 3. \\ El deterioro del planeta Tierra: Un componente que dificulta una antropología del cuidado
}

- Qué estamos haciendo con nuestro planeta y, por ende, con Cnuestra existencia? Si no cuidamos nuestro entorno, nuestra vida peligra. Si no tomamos medidas urgentes como disminuir la deforestación, la contaminación, el uso de plásticos, de pesticidas y demás químicos contaminantes, nuestro futuro y el de nuestros hijos estarán comprometidos. En esta línea es comprensible que la ética de cuidado no se restringe a una esfera particular, sino que extiende su accionar al cuidado de nuestro medio ambiente y de nuestros coterráneos. En una antropología del cuidado, los individuos también se preocupan por su hábitat, ya que comprenden que son seres biotópicos ${ }^{1}$, cuya vida depende del lugar donde se desenvuelven, de manera tal, que si no hay planeta, no hay existencia humana.

Al descuidar el planeta, nos estamos descuidando, puesto que, si el planeta se enferma, los que vivimos de sus suministros, también nos enfermamos. El deterioro de la Tierra demuestra el olvido,

1 La vida (bio) depende del lugar (topos). Los seres vivos dependemos del lugar donde estamos, en nuestro caso dependemos de GAIA, el planeta tierra. 
el desinterés y la indiferencia frente al cuidado de nuestro hogar, que está contribuyendo a que las personas cada vez más pierdan su calidad de vida.

\section{Una antropología que incluya el planeta}

En la encíclica denominada Laudato Si' (2015), el Papa Francisco señala que varios estudios científicos indican que el ser humano está coadyuvando con sus acciones a menoscabar los recursos agotables de nuestro terruño:

Numerosos estudios científicos señalan que la mayor parte del calentamiento global de las últimas décadas se debe a la gran concentración de gases de efecto invernadero (anhídrido carbónico, metano, óxidos de nitrógeno y otros emitidos sobre todo a causa de la actividad humana). Al concentrarse en la atmósfera, impiden que el calor de los rayos solares reflejados por la tierra se disperse en el espacio. Esto se ve potenciado especialmente por el patrón de desarrollo basado en el uso intensivo de combustibles fósiles, que hace al corazón del sistema energético mundial. También ha incidido el aumento en la práctica del cambio de usos del suelo, principalmente la deforestación para agricultura [...] La contaminación que produce el anhídrido carbónico aumenta la acidez de los océanos y compromete la cadena alimentaria marina. (Papa Francisco, 2015, pp. 26-27)

Teniendo como base el Informe del Panel Intergubernamental sobre cambio climático del 2015 se pretende presentar la situación degradante en la que se encuentra el planeta tierra y cómo esta situación juega en contra de la supervivencia humana. En una ética del cuidado, el planeta hace parte primordial de ese cuidado. Nuestra cultura egoconsumista, que tiene como eje la adquisición de créditos económicos, está comprometiendo la existencia de la 
vida en todas sus formas. Comprendemos así, que nuestro planeta se encuentra en cuidados intensivos, pues las acciones humanas han hecho que su temperatura se encuentre muy por encima de los índices normales. Estas acciones han sido propiciadas, entre otras razones, por la inconsciencia, la avaricia, el lucro particular, y el egoísmo humano:

La influencia humana en el sistema climático es clara, y las emisiones antropógenas recientes de gases de efecto invernadero son las más altas de la historia. Los cambios climáticos recientes han tenido impactos generalizados en los sistemas humanos y naturales. (Varios, 2016c, p. 2)

Como lo señala el quinto informe de la IPCC, por sus siglas en inglés de Intergovernmental Panel on Climate Change (Grupo Intergubernamental de Expertos sobre el Cambio Climático), la influencia del ser humano es clara y contundente en el avance del cambio climático global. Las emisiones de gases contaminantes provenientes de la quema de combustibles fósiles está poniendo en peligro la supervivencia humana. $\mathrm{Al}$ respecto, el informe recomienda que ante las agresiones con el planeta, los pueblos se acondicionen a los nuevos cambios para mitigar y minimizar los efectos devastadores del cambio climático. El informe hace un llamado especialmente a los países desarrollados, que son los que más emiten contaminación (India, China, Rusia, Estados Unidos y Brasil), y que están generando más de la mitad de la contaminación mundial, puesto que no solo se están afectando ellos, sino que la acción de estos países está destruyendo toda nuestra atmósfera y nuestros ciclos hidrológicos:

El calentamiento en el sistema climático es inequívoco, y desde la década de 1950 muchos de los cambios observados no han tenido precedentes en los últimos decenios a milenios. La atmósfera y el océano se han calentado, los volúmenes de nieve y hielo han disminuido y el nivel del mar se ha elevado. (Varios, 2016c, p. 2) 
Ahora bien, muchos científicos pagados por las transnacionales contaminantes han sido capaces de afirmar que no existe tal cambio climático, y que lo que está sucediendo es normal, al obedecer a ciclos que se producen en la misma tierra. Sin embargo, por los fenómenos de los últimos tiempos, como son la falta de agua y las miles de hectáreas semidesérticas en diferentes partes del mundo, se comprende que son efectos del cambio climático; realidad comprobada especialmente en los lugares donde se dan las estaciones, puesto que allí se han sentido con mayor rigor los fuertes veranos, con temperaturas exorbitantes y agotadoras y los inviernos con grandes heladas y caídas inusuales de nieve.

Ahora bien, en relación con los países en desarrollo se evidencia que, aunque son menos contaminantes, también van a sufrir los cambios estrepitosos del clima, con el agravante de que cuentan con menores recursos para enfrentar estos cambios. Algunos pensadores y políticos consideran que es mejor construir selvas de cemento y grandes hidroeléctricas que promover el cuidado de reservas ambientales y la creación de parques naturales. Dos ejemplos claros los tenemos en São Paulo (Brasil) ${ }^{2}$ y en el Estado de California (Estados Unidos) $)^{3}$, quienes gracias a la construcción desordenada y a la carencia de políticas ambientales, han sufrido grandes sequías en el pasado y en la actualidad tienen una gran problemática en torno al abastecimiento de agua para sus habitantes y para el cultivo de alimentos en sus zonas rurales:

Cada uno de los tres últimos decenios ha sido sucesivamente más cálido en la superficie de la Tierra que cualquier decenio anterior desde 1850. Es probable que el período 1983-2012 haya sido el período

2 Para profundizar al respecto: http://internacional.elpais.com/internacional/2015/02/28/actualidad/1425080967_907683.html

3 Para leer más: http://earthjustice.org/features/espanol/california-drought 
de 30 años más cálido de los últimos 400 años en el hemisferio norte, donde es posible realizar esa evaluación. (Varios, 2016c, p. 2)

Para los que defienden que no está sucediendo nada, o que eso es normal, cabe refutarles que, efectivamente el mundo está cambiando y este cambio es drástico, puesto que existen estudios serios al respecto como el quinto informe del IPCC, donde se afirma que el clima está alterado, nevadas impensables, calores sofocantes, épocas duraderas sin lluvia, movimientos telúricos en aumento, tornados, tifones y huracanes a la orden del día. No se puede seguir negando esta situación, puesto que al planeta lo estamos aniquilando gradualmente:

En el período comprendido entre 1992 y 2011, los mantos de hielo de Groenlandia y la Antártida han ido perdiendo masa y es probable que esa pérdida se haya producido a un ritmo más rápido entre 2002 y 2011. Los glaciares han continuado menguando en casi todo el mundo. (Varios, 2016c, p. 4)

Deshielos, calentamiento de la superficie marina, erosiones, calidad paupérrima del aire ${ }^{4}$, desaparición de fuentes hídricas importantes ${ }^{5}$, acidificación de los océanos: estamos en una carrera

4 La contaminación del aire en muchas ciudades supera el recomendado por la Organización Mundial de la Salud (OMS), el aumento significativo de automóviles, el humo expulsado por las grandes fábricas y el uso de combustibles fósiles, hacen que en estas ciudades respirar sea un salto al vacío. En el aire se concentran partículas atmosféricas grandes (PM10) o pequeñas (PM2, 5) que suscitan en los individuos graves enfermedades en el aparato respiratorio. Solo en China mueren al año cerca de 1.200 .000 personas por problemas agudos respiratorios vinculados con la contaminación del aire. Esta información se puede ampliar en la siguiente página: https://www.veoverde.com/2013/04/ la-contaminacion-en-china-llevo-a-12-millones-de-muertes-prematuras/

5 En 2015 se secó el segundo lago más grande de Bolivia, denominado Poopó. Estaba ubicado en la provincia de Oruro y su extensión era de 2.337 km². Dicho lago quedó reducido a su mínima expresión, 1 km². Este mismo año 
por destruir nuestra casa grande. Al respecto, la ética del cuidado no solo tiene que ver con los individuos, sino que guarda relación con el cuidado y la defensa de nuestro planeta, puesto que todo está interconectado. Se acaba de revelar que la arena del desierto del Sahara viaja a través del mundo y llega a abonar las tierras del Amazonas, por lo que comprendemos que somos uno con el planeta, somos animales biotópicos, y nuestra vida depende del lugar donde estemos. La relación es unívoca y de dependencia, la tierra perfectamente puede existir sin nosotros, pero no al contrario, nosotros sin la tierra no podemos vivir, pues dependemos de ella para sobrevivir.

Las emisiones antropógenas de gases de efecto invernadero han aumentado desde la era preindustrial, en gran medida como resultado del crecimiento económico y demográfico, y actualmente son mayores que nunca. Como consecuencia, se han alcanzado unas concentraciones atmosféricas de dióxido de carbono, metano y óxido nitroso sin parangón en por lo menos los últimos 800.000 años. Los efectos de las emisiones, así como de otros factores antropógenos, se han detectado en todo el sistema climático y es sumamente probable que hayan sido la causa dominante del calentamiento observado a partir de la segunda mitad del siglo XX (Varios, 2016, p. 4).

El problema ético al que asistimos consiste en que hemos colocado los medios, como si fueran fines. Ahora bien, s es verdad que se necesita la economía para subsistir, el problema está en que lo que se busca, tristemente, es el lucro, y los recursos se están asumiendo como simples medios para asegurar el progreso, a costa de la destrucción de los recursos naturales y deteriorando así nuestro

se secó el cuarto lago más grande del mundo en Rusia, el mar de Aral, en el centro de Asia, y si nos parece descomunal la desaparición en Bolivia, este dato sí que nos va a asombrar, pues el lago tenía 60.000 km², más que el tamaño de un país como Costa Rica $\left(51.100 \mathrm{~km}^{2}\right)$; en la actualidad, solo queda lo equivalente a $5.000 \mathrm{~km}^{2}$. Como responsable de dicha desaparición culpan al sector algodonero de Rusia. 
planeta. Es apenas comprensible que el crecimiento económico a cambio de la destrucción de nuestra casa es mal negocio; es como si vendiésemos nuestra vivienda para comprar el andén, cosa que no tiene ningún sentido.

El quinto informe del IPCC también nos advierte que el crecimiento demográfico está empujando nuestra destrucción, pues cada vez estamos usando más recursos no renovables para satisfacer la demanda de alimentos ${ }^{6}$. Ahora bien, el aumento demográfico acarrea otros problemas tales como los problemas de insalubridad, migraciones, urbanización, acceso al agua, lucha por territorios, problemas de género, religión y de derechos humanos, entre otros conflictos que pueden eclosionar. Se deben entonces promover acciones, como políticas públicas encaminadas a controlar la natalidad y tomar conciencia de manejar responsablemente la sexualidad, sobre todo en temas como la reproducción y la prevención del contagio de enfermedades de transmisión sexual, según lo afirma el informe del IPCG:

La contribución del crecimiento demográfico entre 2000 y 2010 siguió siendo a grandes rasgos idéntica a los tres decenios anteriores, mientras que la contribución del crecimiento económico ha aumentado notablemente. El mayor uso del carbón ha invertido la prolongada tendencia de descarbonización gradual (p. ej. al provocar una disminución de la intensidad de carbono de la energía) del suministro energético mundial. (Varios, 2016c, p. 5)

Si no hay control demográfico, cada día se requerirá mayor uso de energía, con todo el problema que esto acarrea. Adicional al crecimiento demográfico, el problema se agrava con la alteración

6 Según el Instituto Francés de Estudios Demográficos, la población para el año 2050 superará la barrera de los 9.000 millones de habitantes y la India superará a la China como el país más poblado, con una población cercana a los 1.691 millones de habitantes. Recuperado de http://www.otromundoesposible.net/el-imparable-aumento-de-la-poblacion-mundial/ 
normal del ciclo del agua. Se han aumentado los ya famosos fenómenos del Niño y de la Niña, el primero con intensos veranos y el segundo con inusuales lluvias y fuertes tempestades.

La evidencia más sólida y completa de los impactos observados del cambio climático corresponde a los sistemas naturales. En muchas regiones, las cambiantes precipitaciones o el derretimiento de nieve y hielo están alterando los sistemas hidrológicos, lo que afecta a los recursos hídricos en términos de cantidad y calidad. Muchas especies terrestres, dulceacuícolas y marinas han modificado sus áreas de distribución geográfica, actividades estacionales, pautas migratorias, abundancias e interacciones con otras especies en respuesta al cambio climático en curso. (Varios, 2016c, p. 6)

Para el caso colombiano, en el 2016 acabamos de sufrir un intenso fenómeno del niño que devastó cultivos y ocasionó la muerte de un sinnúmero de animales. De continuar el calentamiento global, Colombia deberá despedirse de sus nevados, los cuales se calcula que no estarán para el 20307 . El continuo deshielo de los glaciares está aumentando el nivel de agua de los océanos, ocasionando que las ciudades costeras se vean afectadas; y en el caso de nuestro país, ciudades como Cartagena, Santa Marta y Buenaventura sentirán de cerca el rigor de este aumento:

Es muy probable que el número de días y noches fríos haya disminuido y el número de días y noches cálidos haya aumentado a escala global. Es probable que en gran parte de Europa, Asia y Australia la incidencia de las olas de calor haya aumentado. Es muy probable que la influencia humana haya contribuido a los

$7 \mathrm{Al}$ respecto se puede consultar la siguiente página: http://www.eltiempo.com/estilo-de-vida/ciencia/nevado-del-ruiz-el-deshielo-de-los-nevados-en-colombia/15352275 
cambios a escala global observados en la frecuencia e impactos generalizados atribuidos al cambio climático. (Varios, 2016c, p. 8)

El aumento del calor lo estamos notando día a día en nuestro país, pues las ciudades frías se están volviendo templadas, las ciudades templadas se han vuelto cálidas y las ciudades cálidas se han vuelto un "infierno", puesto que sus temperaturas se vuelven insoportables con consecuencias nefastas para la vida de los habitantes que se sienten extraños en su misma tierra. Se trata de una situación que altera la vida de sus pobladores y la expone gracias a la aparición de enfermedades, como el cólera, el dengue, chikungunya, zika, ébola, mayaro, el síndrome de Guillain-Barré, la microcefalia, y las IRA (infecciones respiratorias agudas). A esto se suma el manejo inadecuado de los residuos tóxicos que van a parar a nuestras fuentes de agua, como es el caso del río Bogotá, que se caracteriza por ser uno de los más contaminados del mundo, como lo muestra la fotografía 1, que presenta el río Bogotá negro, sucio, sin meandros, con olor fétido y sin esperanza. Esta fotografía está tomada a la altura de la calle 80 , puente de Siberia, donde se divisa el río totalmente contaminado.

Los impactos de los recientes fenómenos extremos conexos al clima, como olas de calor, sequías, inundaciones, ciclones e incendios forestales ponen de relieve una importante vulnerabilidad y exposición de algunos ecosistemas y muchos sistemas humanos a la actual variabilidad climática (Varios, 2016, p. 8). 
Fotografía 1. Río Bogotá a la altura de la calle 80

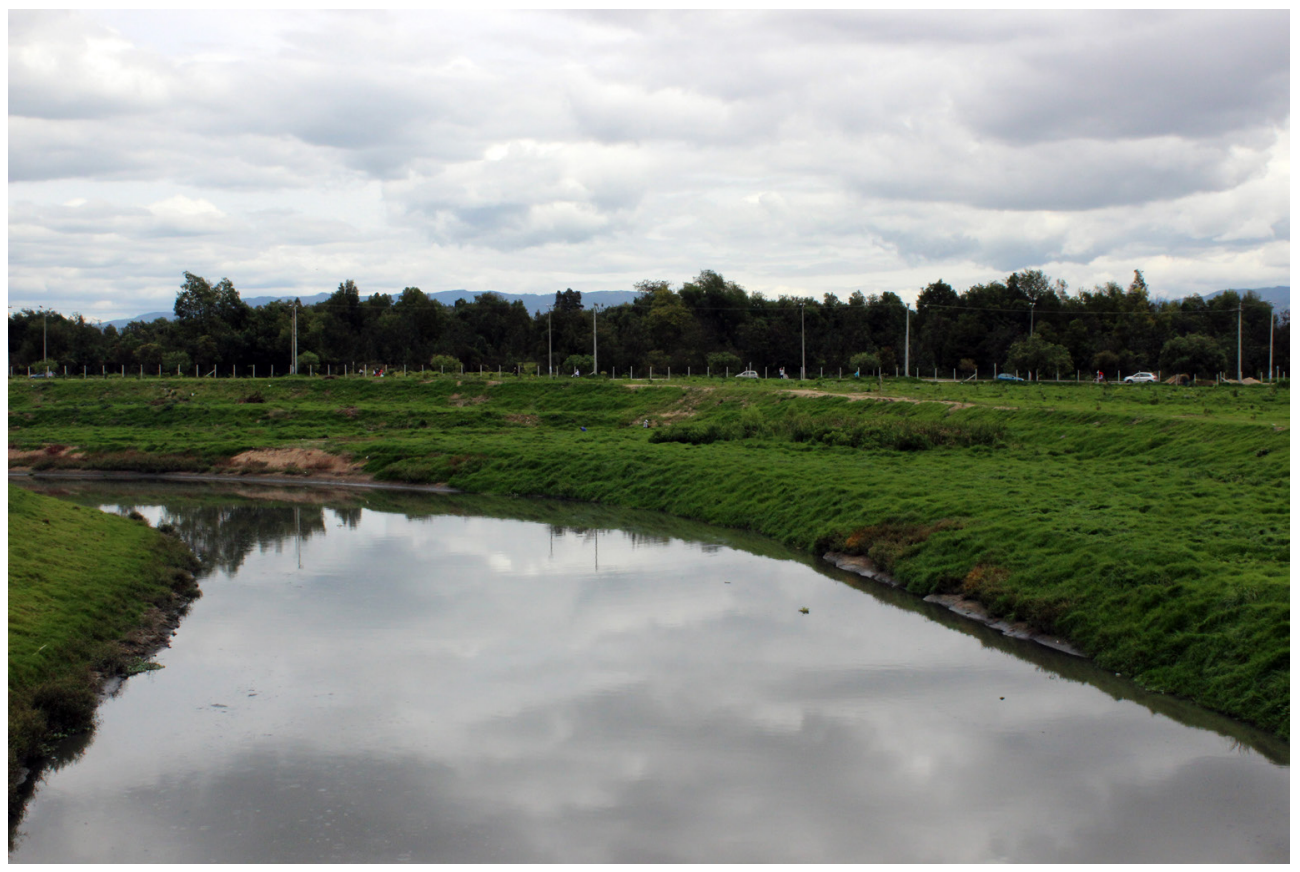

Fuente: archivo del autor.

El número de huracanes mayores (categorías 4 y 5) que se presentaron en la parte oriental del Pacífico Norte en 2015 ascendió a 9, siendo el mayor del cual se tiene registro desde 1971. Este mismo año aumentaron los ciclones tropicales: verbigracia, los ciclones Pam y Winston arrasaron con las ciudades de Vanuaty y Fiji en el Pacífico Sur. La intensidad y la fuerza ciclónica de las tormentas y huracanes fue un $63 \%$ más alta que la media de 1981-2010. Igualmente, han aparecido ciclones tropicales donde no se tenía registro alguno, lugares un poco atípicos para la presencia de estos fenómenos, como Cabo Verde, Azores y Yemen. ${ }^{8}$

8 Se puede profundizar más en la página: http://www.tiempo.com/ $\mathrm{ram} / 248542 /$ noticias-desde-el-comite-de-huracanes-para-2016/ 
En todos los escenarios de emisiones evaluados, las proyecciones señalan que la temperatura en superficie continuará aumentando a lo largo del siglo XXI. Es muy probable que las olas de calor ocurran con mayor frecuencia y duren más, y que los episodios de precipitación extrema sean más intensos y frecuentes en muchas regiones. El océano se seguirá calentando y acidificando, y el nivel medio global del mar continuará elevándose. (Varios, 2016c, p. 10)

Para la confirmación de este escenario de temperaturas altas, cabe mencionar que en el 2016 se rompieron tres récords en torno a la excesiva temperatura en el planeta. El primero guarda relación con el mes más caluroso en 137 años, según datos de la Administración Nacional Oceánica y Atmosférica de los Estados Unidos (NOOA, por sus siglas en inglés), el mes de junio fue el más caluroso desde que se iniciaron los registros de temperaturas en 1880. Según los científicos, desde hace 137 años la temperatura ha aumentado, en vez de descender, y en gran parte este aumento ha sido propiciado por acciones humanas.

El segundo récord que se rompió estuvo relacionado con la temperatura en la superficie del mar, pues en junio estuvo $0,77^{\circ} \mathrm{C}$ más cálida que el promedio del siglo pasado, y el nivel más alto para dicho mes en lo que se lleva haciendo registro. Finalmente, el tercer récord tuvo relación con el mes de junio que fue el más cálido para el hemisferio norte del continente americano. Efectivamente, la temperatura alta se está notando a lo largo de todo el planeta, y el fenómeno climático se siente en todos los países, tanto en los tropicales, como en aquellos en los que hay estaciones. Un ejemplo de las altas temperaturas está en el continente africano donde junio de 2016 también fue el mes más caluroso desde $1910^{9}$. Esto demuestra que el calentamiento global no es una mentira, sino una

9 Para profundizar más al respecto se puede consultar la siguiente página: http://www.bbc.com/mundo/noticias-36841805 
realidad concreta que está cambiando los hábitos alimenticios, de vestimenta e inclusive de interacción.

El cambio climático agravará los riesgos existentes, y creará nuevos riesgos para los sistemas naturales, para los animales y para los seres humanos. Los riesgos se distribuyen de forma dispar y son generalmente mayores para las personas y comunidades menos favorecidas de nuestros países, sea cual sea el nivel de desarrollo de estos. (Varios, 2016c, p. 13)

Por supuesto que el cambio climático es evidente, y es también claro que este va a empeorar los sistemas naturales y humanos, y que va a afectar más a aquellas comunidades pobres y vulnerables, que las que tienen recursos económicos para paliar estas situaciones. Por esto, el informe del IPCG aboga por que los países contaminantes ayuden a los países que inciden poco en la contaminación, pero igualmente se están viendo afectados por el calentamiento, con el agravante de que ante la ausencia de dinero, no pueden destinar muchos recursos para minimizar los efectos de dicho calentamiento:

El cambio climático tiene las características de un problema de acción colectiva a escala mundial, puesto que la mayoría de los Gases de Efecto de Invernadero (GEI) se acumulan con el tiempo y se combinan globalmente, y las emisiones realizadas por cualquier agente (p. ej., personas, comunidades, empresas o países) afectan a los demás agentes. No se alcanzará una mitigación eficaz si los distintos agentes anteponen sus propios intereses de forma independiente. Por consiguiente, se requieren respuestas cooperativas para mitigar de forma eficaz las emisiones de GEI y abordar otros problemas del cambio climático. La eficacia de la adaptación se puede mejorar mediante medidas complementarias a todos los niveles, inclusión hecha de la cooperación internacional. Los datos sugieren que los resultados 
que se consideran equitativos pueden desencadenar una cooperación más eficaz. (Varios, 2016c, p. 17-18)

Los países fabricantes o dueños de fábricas de automóviles, motocicletas, pesticidas, fungicidas, armas, computadores, celulares y tecnología en general, o que se lucran mediante la explotación de los hidrocarburos, la minería y la tala indiscriminada de árboles (industria maderera y del papel) deberán pagarles a los países que no poseen recursos económicos, por la contaminación que se deriva de su accionar en el planeta, al igual que deben colaborarles a estos países con la creación de estrategias de mitigación, y hacerles partícipes de tecnologías limpias que coadyuven a minimizar la emisión de gases contaminantes, tales como la implementación de sistemas alternativos para la generación de energías amigables con el planeta, como las energías alternativas derivadas del aire, el mar, el sol y el movimiento, entre otras.

El cambio climático agrava otras amenazas a los sistemas sociales y naturales, colocando nuevas cargas, en particular sobre los pobres. Armonizar la política climática con el desarrollo sostenible requiere considerar tanto la adaptación como la mitigación. De demorarse las medidas de mitigación podrían verse limitadas las posibilidades de trayectorias resilientes al clima en el futuro. Las oportunidades para aprovechar las sinergias positivas entre la adaptación y la mitigación pueden reducirse con el tiempo, especialmente si se sobrepasan los límites de la adaptación. Los crecientes esfuerzos desplegados en pro de la mitigación del cambio climático y la adaptación a él van aparejados a una creciente complejidad de las interacciones, especialmente en las intersecciones entre los sectores de la salud humana, el agua, la energía, el uso del suelo y la biodiversidad. (Varios, 2016c, p. 32) 
Otra de las consecuencias que se desprende del calentamiento global está intrínsecamente relacionada con el acceso al agua potable de muchas comunidades enteras o parciales. En nuestro caso, sufren por agua diferentes regiones, como los departamentos de La Guajira, Magdalena, Bolívar, Atlántico, Cundinamarca, Sucre, Córdoba, Casanare, entre otros. Ahora, cabe aclarar que muchos de estos departamentos sufren mayormente los rigores del clima afectando a las poblaciones, porque gracias a la corrupción han sustraído el dinero destinado para la edificación de acueductos, para el levantamiento de diques y canales, y otras obras que efectivamente se han destinado para mitigar el efecto del calentamiento.

Desde otro ángulo, muchas personas se atreven a afirmar que la próxima guerra mundial se va a desatar por el agua potable, y no distan mucho de esto, puesto que en la actualidad hay muchas regiones en el mundo donde el preciado líquido brilla por su ausencia, y porque algunas empresas transnacionales, como en el caso de Coca-Cola, Nestlé, Citigroup, entre otras, se vienen apoderando de grandes cantidades de acuíferos en todo el mundo, y de esta forma han privatizado aquello que debe ser un derecho fundamental para todos los habitantes del planeta, como es el acceso al agua:

Así pues, grandes conglomerados bancarios como Goldman Sachs, JP Morgan Chase, Citigroup, UBS, Deutsche Bank, Credit Suisse, Macquarie Bank, Barclays Bank, Blackstone Group, Allianz y HSBC, entre otros, están consolidando su control sobre el agua de todo el planeta. Magnates como T. Boone Pickens, el ex presidente George HW Bush y su familia, Li Ka-shing de Hong Kong, Manuel V. Pangilinan, otros multimillonarios filipinos y muchos más, están comprando miles de hectáreas de tierra con acuíferos, lagos, derechos sobre el agua, servicios sanitarios y acciones en empresas de tecnología e ingeniería del agua de todo el mundo. (Enlace, 2016) 
No es descabellada la idea de que la próxima guerra mundial tendrá como gran causante el acceso al agua, pues sin ella no es posible la vida sobre la faz de la tierra. Y es un poco contradictorio, porque nuestro planeta, en su mayoría, está compuesto de agua, pero solo el $1 \%$ de ella es potable, es decir, apta para el consumo humano. Los gobiernos deberán estar muy atentos a este avance de las transnacionales en su afán por adquirir nuestras fuentes de agua y privatizarlas, puesto que de esta forma están comprometiendo nuestro futuro y el de las próximas generaciones. En Colombia, por ejemplo, el gobierno del presidente Juan Manuel Santos vendió a una empresa de origen canadiense ${ }^{10}$ el manejo del $25 \%$ de la producción hidroeléctrica del país.

Ahora bien, la política de privatizar las empresas públicas se encuentra presente en casi todo el mundo; en Colombia, el servicio de gas, la electricidad, la telefonía y el agua en su mayoría han sido vendidas a capital extranjero. Pero volviendo al tema del agua, la misma se está vendiendo a capital transnacional en sus diferentes presentaciones, como lo expresa la revista Enlace de México:

Cuando hablamos de "agua", hacemos referencia a los derechos de este insumo, es decir, el derecho de aprovechar las aguas subterráneas, los acuíferos y los ríos, la tierra que contiene grandes extensiones de agua (lagos, lagunas y manantiales naturales en la superficie o en las aguas subterráneas), proyectos de desalinización, de purificación y tecnologías de tratamiento, tecnologías

10 El fondo de inversión canadiense Brookfield, se quedó con la tercera generadora de electricidad del país, en una subasta llena de críticas y de inconformismo por gran parte del pueblo colombiano. El argumento del gobierno para vender ISAGEN fue que necesitaba el dinero para realizar vías de cuarta generación $(4 \mathrm{G})$ que modernizaran el país y permitieran la movilidad de productos de un lado a otro. La subasta estuvo salpicada de denuncias, además de vender un gran activo del país, que generaba grandes dividendos, se le estaba dando el manejo de la energía hidroeléctrica a una empresa foránea. 
de riego y perforación de pozos, empresas de servicios públicos de saneamiento del agua, mantenimiento y construcción de la infraestructura de suministro (de tuberías y distribución a todas las escalas de las plantas de tratamiento a nivel residencial, comercial, industrial y usos municipales), servicios de ingeniería del agua (por ejemplo, los que participan en el diseño y construcción de instalaciones relacionadas con el agua), y el sector de agua al por menor, como los que participan en la producción y las ventas de agua embotellada, máquinas expendedoras, servicios de suscripción y entrega de agua embotellada, y camiones de suministro. (Enlace, 2016)

A la escasez de agua suscitada por el calentamiento global, se le suma la privatización de nuestros acuíferos, poniendo en riesgo la subsistencia de las futuras generaciones. Se trata de un panorama desalentador y desolador, puesto que "las proyecciones indican que el cambio climático hará que se reduzcan los recursos de aguas superficiales y aguas subterráneas renovables en la mayoría de las regiones secas subtropicales, con lo que se intensificará la competencia por el agua entre los sectores" (Varios, 2016c, p. 15).

La escasez no solo afectará los sectores urbanos, donde posiblemente se generará pánico y se desatarán los conflictos, sino que se calcula que en las áreas rurales habrá problemas de abastecimiento, y que, a su vez, se comprometerá la seguridad alimentaria y los ingresos agrícolas; y se agudizará la pobreza en la que está sumido el campo, sobre todo en países como el nuestro, donde este sector se encuentra socavado y sumido en el abandono.

Se calcula que en las ciudades, y sobre todo en las megaurbes, el aumento térmico generará tormentas, tornados, lluvias inclementes, inundaciones, erosiones, deslizamientos de tierra, aumento de las radiaciones solares, contaminación del aire, escasez de agua, aumento del nivel del mar y esto, a su vez, se traducirá en pérdidas económicas, desplazamientos interurbanos y caos generalizado. 
Desde la perspectiva de la pobreza, las proyecciones indican que los impactos del cambio climático ralentizarán el crecimiento económico, harán más difícil reducir la pobreza, seguirán menoscabando la seguridad alimentaria y harán que continúen las trampas de pobreza existentes, especialmente en las zonas urbanas y las nuevas zonas críticas de hambruna. (Varios, 2016c, p. 16)

Efectivamente, el panorama es sombrío y un poco abrumador, realidad que impele a procurar soluciones a corto, mediano y largo plazo. Pues bien, existen gobiernos de algunos países ${ }^{11}$ que ya se han dado a la tarea de implementar fuentes energéticas limpias ${ }^{12}$ y eficientes, al igual que le han apostado a un menor consumo de energía, promoviendo el reciclaje de sus desechos y del agua, e invirtiendo en la salvaguarda de sus ecosistemas, donde se pueda capturar el carbono que todavía se arroja a la atmósfera por diferentes agentes contaminantes, ente los que se encuentran las fábricas y los automóviles. Las apuestas de estos gobiernos han requerido una gran inversión a nivel económico, tecnológico, social e institucional. Estos países han venido adaptándose gradualmente al cambio climático. Ahora bien, viene el cuestionamiento: ¿qué hacer con los países que no tienen los recursos económicos y tecnológicos requeridos para enfrentar tal situación? Aquí salta a la vista que es necesaria y urgente la cooperación internacional, puesto que restringir el calentamiento a su mínima expresión

11 Entre los países que lideran el reemplazo de energías contaminantes, por energías alternativas menos contaminantes, cabe mencionar los siguientes: Islandia, Suecia, Noruega, Suiza, Costa Rica, Canadá, Bélgica, Francia y Nueva Zelanda.

12 Se consideran fuentes energéticas limpias aquellas que no emiten gases contaminantes a la atmósfera, entre ellas cabe destacar: la energía eólica, la energía hidroeléctrica, la energía nuclear, la energía geotérmica, la energía solar y la energía mareomotriz. 
es responsabilidad de todos, pero sobre todo de aquellos que más perjudican el medio ambiente, a la vez que tienen los recursos:

La cooperación internacional es decisiva para lograr una mitigación eficaz, si bien la mitigación también puede tener beneficios a escala local. La adaptación se centra principalmente en los resultados a escala local y nacional, pero su eficacia puede mejorarse mediante la coordinación en todas las escalas de gobernanza, incluida la cooperación internacional. (Varios, 2016c, p. 30).

La idea es promover una política internacional que favorezca el desarrollo sostenible y que aporte en la mejora del bienestar social, ambiental y económico del planeta, donde todos ganemos, incluyendo nuestros diversos ecosistemas. Esta política debe partir de una apuesta global, donde las respuestas que se ofrezcan tengan como derroteros la planificación y la implementación de energías limpias y eficaces, donde el agua, la seguridad alimentaria, la captura de carbono biológico, y el desarrollo urbano y rural sean prioridades dentro de la agenda mundial. Urge entonces hacer un manejo adecuado de las basuras, para que no ocurra lo que se observa en la fotografía 2.

Las respuestas de adaptación y mitigación requieren factores propicios comunes, tales como la eficacia de las instituciones y de la gobernanza, la innovación y las inversiones en tecnologías e infraestructura ambientalmente racionales, así como medios de subsistencia, y las opciones de comportamientos y estilos de vida sostenibles. (Varios, 2016c, p. 27) 
Fotografia 2. Manejo inadecuado de basuras en la localidad de Suba, Bogotá

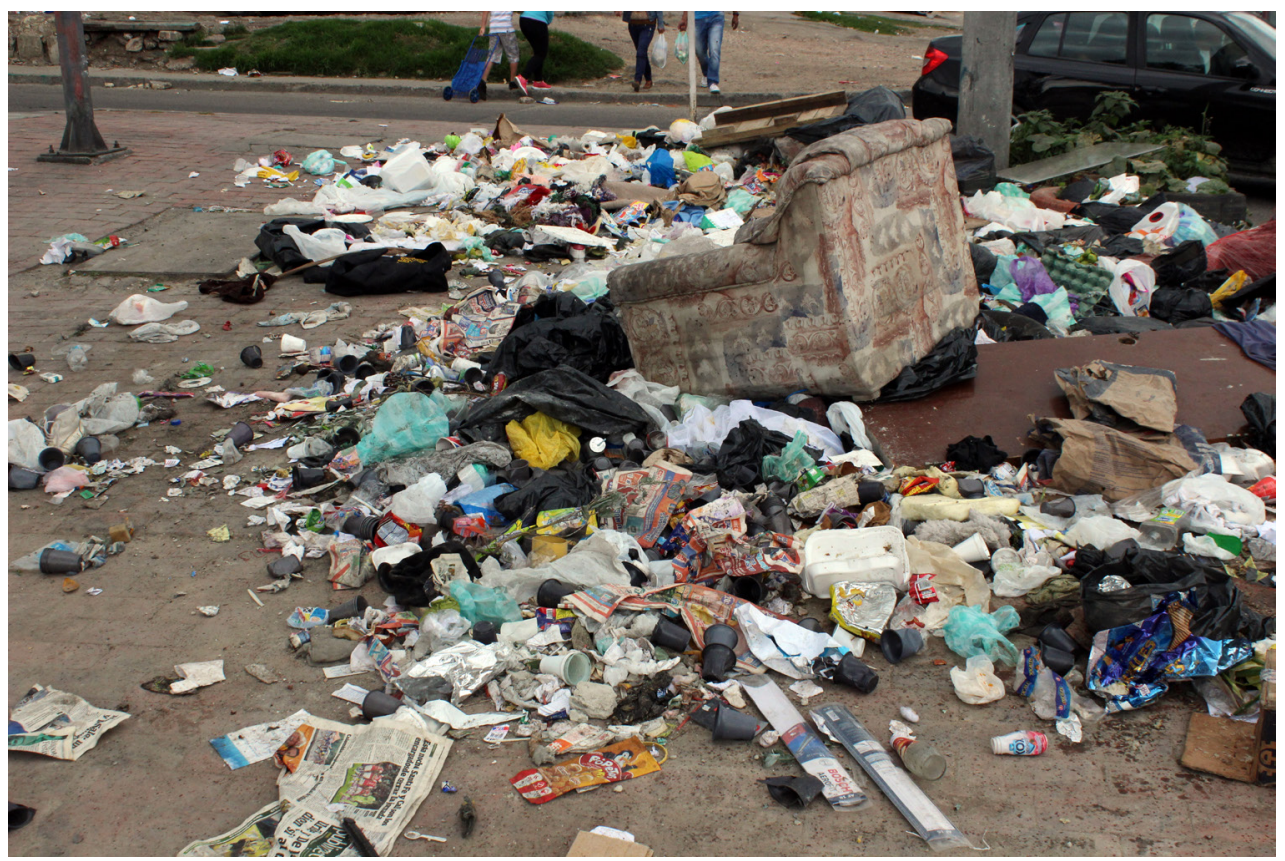

Fuente: archivo del autor.

Algunas actitudes que se deben promover a nivel institucional guardan relación con el uso de energías renovables, el aumento en el uso de la bicicleta (fotografias 3 y 4), la disminución del uso del carro y de los combustibles fósiles, suscitar discusiones sobre entornos saludables y cristalizar dichos entornos, donde sea posible la actividad física, donde haya espacios libres del humo de cigarrillo, y libres de elementos patógenos derivados de la contaminación ambiental.

Sin embargo, muchos de los esfuerzos pueden no ser aceptados por los dueños del poder, aquellos que solo ven el planeta Tierra, como una fuente inagotable de dinero; realidad denunciada por el Papa Francisco: 
Lamentablemente, muchos de los esfuerzos para buscar soluciones concretas a la crisis ambiental suelen ser frustrados no solo por el rechazo de los poderosos, sino también por la falta de interés de los demás. Las actitudes que obstruyen los caminos de solución, aun entre los creyentes, van de la negación del problema a la indiferencia, la resignación cómoda o la confianza ciega en las soluciones técnicas. Necesitamos una solidaridad universal nueva. (Papa Francisco, 2015, p. 17).

Es necesario entonces tomar conciencia de que no hay una segunda oportunidad para el cuidado de nuestra casa, y que esta es indispensable para la supervivencia humana y de todos los seres vivos. En una antropología del cuidado, el individuo está llamado a asumir la responsabilidad de sus actos, cambiar su estilo de vida consumista y procurar reciclar, reutilizar y comprar elementos biodegradables que sean más amables con nuestro planeta. A medida que el ser humano avanza con su modelo de crecimiento económico la tierra se degrada, y a pesar de que todos estamos perdiendo, los que más sufren son las personas menos favorecidas de nuestra sociedad: "tanto la experiencia común de la vida ordinaria como la investigación científica demuestran que los más graves efectos de todas las agresiones ambientales los sufre la gente más pobre" (Papa Francisco, 2015, p. 45). 
Fotografía 3. Desplazamiento de ciudadanos en bicicleta

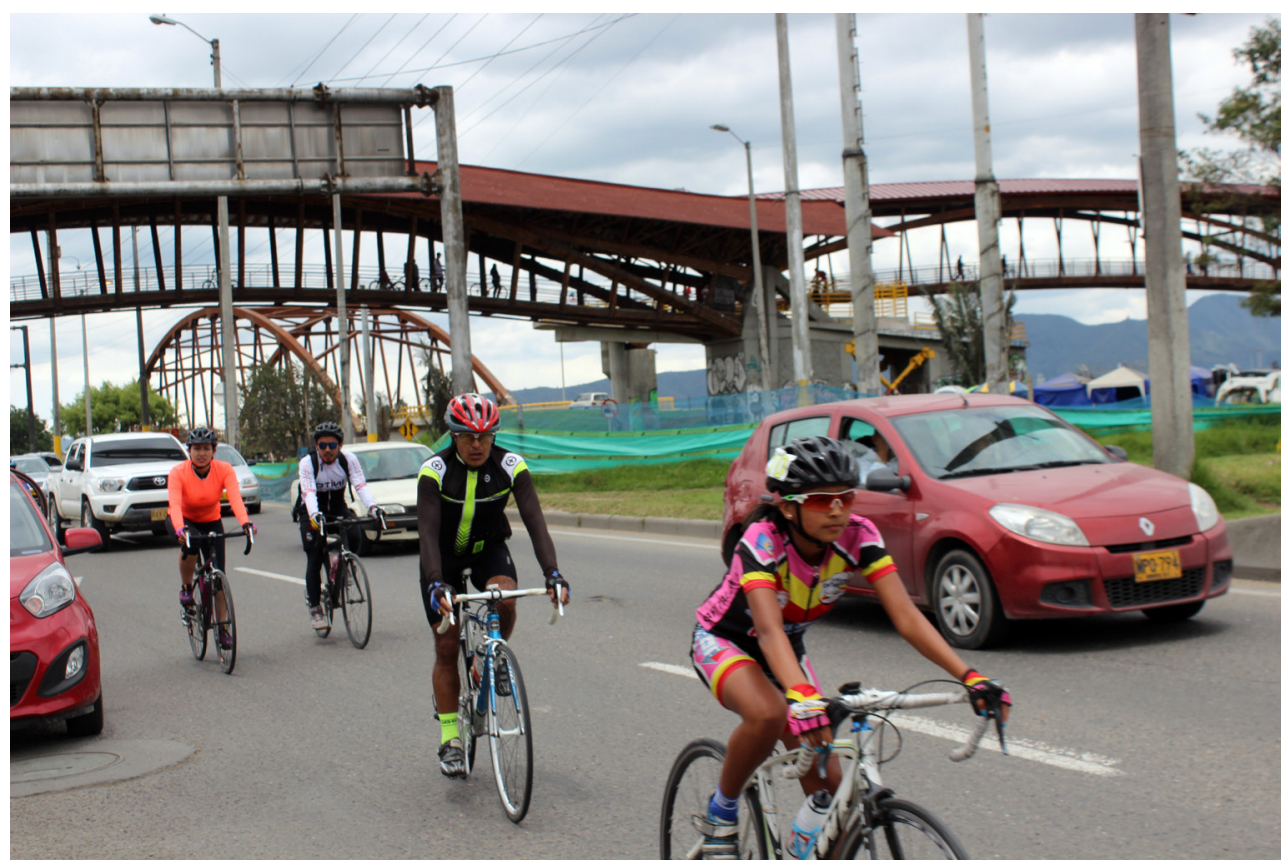

Bogotá, en la actualidad, es la ciudad donde la gente realiza más recorridos en bicicleta en toda Latinoamérica; como lo muestra la foto, es muy común ver a personas haciendo esta actividad física.

Fuente: archivo del autor. 
Fotografía 4. Niños practicando bicicrós

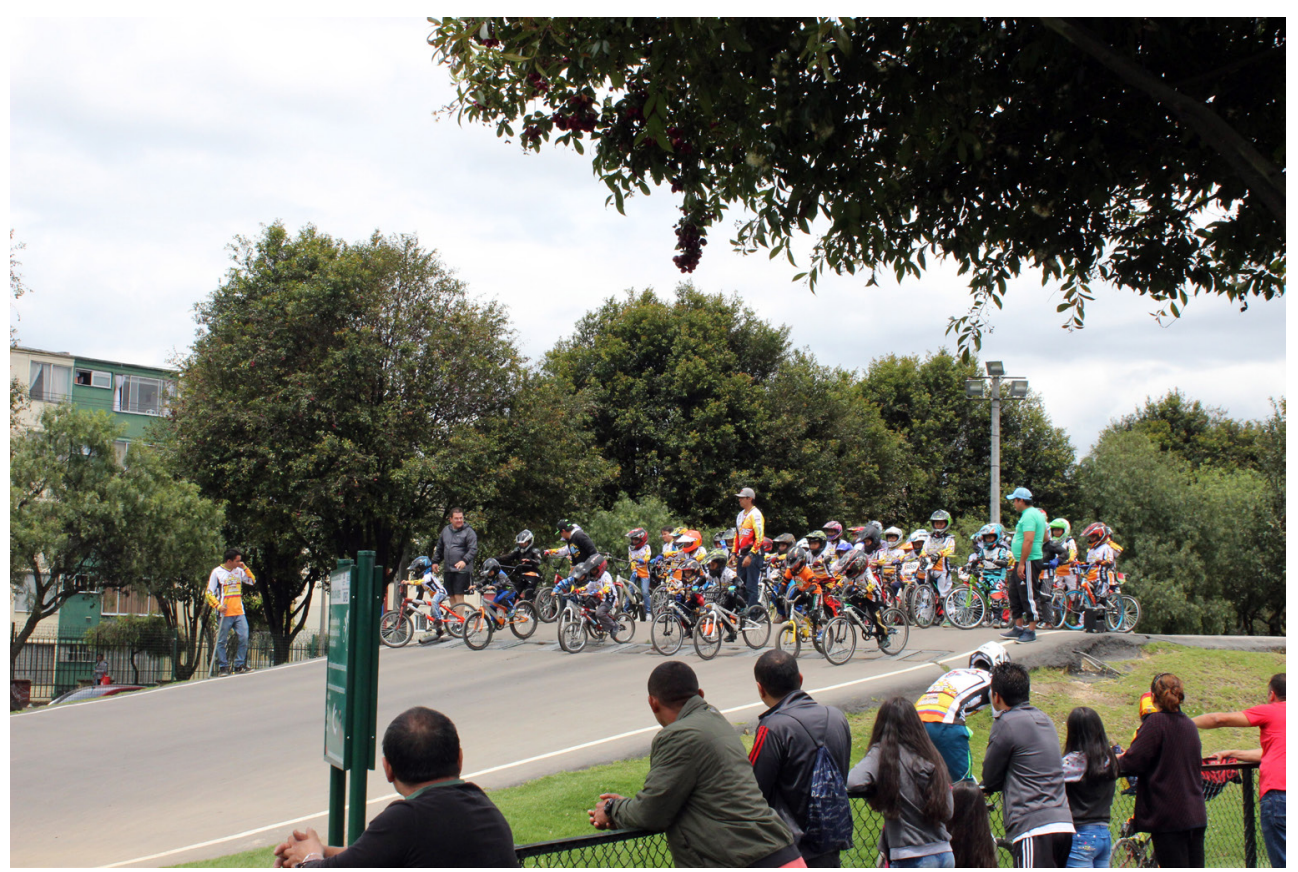

Se ha aumentado la práctica del BMX, como disciplina deportiva, después de los logros obtenidos por la bicicrocista colombiana Mariana Pajón.

Fuente: archivo del autor. 